\title{
Effect of Fenugreek Seed Husk on the Rheology and Quality Characteristics of Muffins
}

\author{
Deeptanshu Srivastava ${ }^{1}$, Jyotsna Rajiv ${ }^{2}$, Mahadevamma ${ }^{3}$, Madeneni Madhava Naidu ${ }^{1 *}$, \\ Jarpala Puranaik ${ }^{1}$, Pullabhatla Srinivas ${ }^{1}$ \\ ${ }^{1}$ Plantation Products, Spices and Flavour Technology Department, Central Food Technological Research Institute, Mysore, India; \\ ${ }^{2}$ Flour Milling, Baking and Confectionery Technology Department, Central Food Technological Research Institute, Mysore, India; \\ ${ }^{3}$ Biochemistry and Nutrition Department, Central Food Technological Research Institute, Constituent Laboratory of Council of Sci- \\ entific and Industrial Research, Mysore, India. \\ Email: ${ }^{*}$ mmnaidu@cftri.res.in
}

Received July $24^{\text {th }}, 2012$; revised August $24^{\text {th }}, 2012$; accepted September $2^{\text {nd }}, 2012$

\begin{abstract}
The effect of incorporation of fenugreek seed husk (FSH) in muffins at different levels of 5\%, 10\% and 15\% was investigated. Muffins were prepared with FSH at different levels and batter flow properties were studied. The muffin batter viscosity increased from 32,500 to $38,000 \mathrm{cps}$ when the FSH content increased from 0 to $15 \%$. While the muffin volumes increased upto $10 \%$ addition of FSH and further FSH increase did not result beneficially. Supplementation with FSH resulted in softer crumb texture indicated by the hardness which decreases in hardness 4.20 to $3.19 \mathrm{~N}$. Inclusion of FSH addition in muffins found acceptance by panelists with a rating better than the control. The optimal level of incorporation of FSH flour, based on sensory quality in muffins was found to be $10 \%$ and use of Polysorbate- 60 at $0.5 \%$ level in these muffins further improved the overall quality characteristics. These muffins had double the amount of dietary fiber.
\end{abstract}

Keywords: Fenugreek Seed Husk; Dietary Fiber; Batter Viscosity; Muffins Quality; Sensory Properties

\section{Introduction}

The dietary fiber (DF) is well recognized as one of the important dietary components that promotes good health [1]. DF is the edible part of plants and their constituent complex carbohydrates; it consists of polysaccharides that are resistant to digestion and absorption in the human small intestine with complete or partial fermentation in the large intestine [2]. Sources of Fiber can be natural (bran), isolated (cellulose and various gums), modified (carboxymethylcellulose), or non-plant (xylans and polydextrose) [3].

The role of DF in alleviation of ailments like constipation, diverticulitis, bowel disorders, cardiovascular diseases and diabetes has been well documented [4-6]. Various forms of DF are often recommended for inclusion in foods to lower the incidence of health disorders and also to reduce the calorific intake. Tolerable intake of DF is considered to be about $14 \mathrm{~g} / 1000 \mathrm{~K}$ cal per day for adults [7]. DF deficiency is a major dietary problem facing the western world and also in developing countries. Consequently, both the nutritional and functional properties of DF come into focus in the potential development of fiber-enriched foods such as bakery products,

\footnotetext{
"Corresponding author.
}

snacks, sauces, drinks, cereals, biscuits, dairy products and meat products [8]. The effect of addition of different DF and edible cereal bran on the baking and sensory characteristics of cupcakes has been studied [9]. Recently, the effect of emulsifiers and other ingredients such as oat bran, rice, sorghum, maize resistant starch, chickpea flour on rheological, nutritional and quality characteristics of high protein, high fibre and low carbohydrate bread was reported $[10,11]$.

Fenugreek (Trigonella foenum-graecum) is an annual leguminous herb possessing important medicinal attributes. The average length, width and thickness of fenugreek seeds and single seed mass and geometric mean diameter ranged from 4.01 to $4.19,2.35$ to $2.61,1.49$ to $1.74 \mathrm{~mm}, 0.0157$ to $0.0164 \mathrm{~g}$ and 2.40 to $2.66 \mathrm{~mm}$ with the increase in moisture content from $8.9 \%$ to $20.1 \%$ d.b., respectively [12]. The dried seeds are aromatic but bitter; traditionally they are well-known for their carminative, antibacterial, anti-inflammatory, insulinotropic, and rejuvenating effects [13]. Various solvent extraction techniques have been developed over the years to comercially extract the total fiber from fenugreek. Recently, separation of fenugreek seeds into husk and endosperm afforded the advantage of process viability for facile isolation of respective bioactive components has been re- 
ported [14]. This study also indicated that fenugreek husk, being rich in DF and phenolic acids could be an effective source of antioxidant and natural ingredients in functional foods. There are a few reports on the use of whole fenugreek seed powder in bakery, pasta and traditional products [15-18]. However, there are no scientific reports on the incorporation of fenugreek seed husk in the food products.

Different DF differs in their structure and chemical composition, thus having varied nutritional and functional attributes. As a consequence of the variation in the properties and effects of DF from different sources, a systematic study of the effect of each individual fiber on the rheological, baking and quality characteristics of cake is important for consumer acceptability. The purpose of this study was to examine the effect of incorporating different levels of FSH on the quality and sensory characteristics of muffins.

\section{Materials and Methods}

\subsection{Materials or Ingredients}

Fenugreek (Trigonella foenum-graecum) seeds used in the present study were procured from Rajasthan, India. Fractionation of fenugreek seeds was done by physical separation method [14]. Commercial refined wheat flour (WF) was obtained from the local super market. The WF and FSH powder blends were prepared in the ratio of 100:0, 95:5, 90:10 and 85:15. Shortening (Margarine, Hindustan Lever Ltd., Mumbai, India) eggs, sugar powder (local market, Mysore) baking powder (single and slow acting type, acid source sodium aluminium sulfate (Hindustan Lever Ltd., Mumbai), salt, calcium propionate, glacial acetic acid (S.D Fine Chemicals Ltd., Mumbai, India) and pineapple essence (Bush Boake Allen Ltd., Chennai, India) were used in the studies. Polysorbate-60 (PS-60) and Sodium stearoyl-2-Lactylate (SSL) were procured respectively from S.D. Fine Chemicals Ltd., Mumbai, India and S.D Fine chemicals, Bengaluru, India. Both emulsifiers were used at $0.5 \%$ level on flour basis in the studies. SSL was made into a gel using emulsifier and water in the ratio of 1:4. The water was heated to $60^{\circ} \mathrm{C}$ and the temperature was maintained. SSL was added with continuous stirring till a homogenous emulsion was formed. The cooled gel was used in the studies.

\subsection{Chemical and Rheological Characteristics of WF-FSH Blends}

WF was replaced by FSH at 5, 10 and $15 \%$ levels and the prepared blends were used in the studies. The WF-FSH blends were analyzed for moisture (method 44-15), total ash (method 08-01), fat (method 30-10), dry gluten (method 38-10), Hagberg Falling number (method 5681B), SDS-sedimentation value (method 56-61) and pro- tein (method 46-10) content according to the standard methods [19].

\subsection{Colour Measurement}

The crumb colour of muffins as influenced by different levels of FSH was measured in terms of lightness (L) and colour ( $+\mathrm{a}$ : red, $-\mathrm{a}$ : green, $+\mathrm{b}$ : yellow, $-\mathrm{b}$ : blue) using Hunter Lab Colour Measuring system (Colour measuring Labscan XE system, Reston, USA). Illuminant D 65, View angle $10^{\circ}$ and Port size 1 inch were used.

\subsection{Dietary Fiber}

The total dietary fiber (TDF), a measure of the sum of insoluble and soluble dietary fiber, based on digestion of food samples with enzymes, was determined as described in AOAC method [20].

\subsection{Studies on Muffin Batter Specific Gravity}

Specific gravity of muffin batter (at $28^{\circ} \mathrm{C} \pm 2^{\circ} \mathrm{C}$ ) was calculated by dividing the weight of a standard measure of the batter by the weight of an equal volume of water according to Jyotsna et al., (2004) [21].

\subsection{Batter Viscosity}

Viscosity was measured according to method of Ashwini et al., (2009) [22]. The viscosity of muffin batter was determined using a Brookfield viscometer (Model DV-III, Stoughton, MA, USA). Cake batter was transferred to a $100 \mathrm{ml}$ beaker and leveled up to the brim. The spindle speed was set to $20 \mathrm{rpm}$ and spindle no. 7 was used for all experiments. Viscosity was measured immediately. The experiment was run at room temperature $\left(28^{\circ} \mathrm{C} \pm 2^{\circ} \mathrm{C}\right)$.

\subsection{Preparation and Measurement of Physical and Sensory Characteristics of Muffins}

The formulations and method of mixing of muffins was done according to Jyotsna et al., (2011) [23]. The following formulation was used for the preparation of muffins WF:FSH ratio (100:0; 95:5; 90:10 \& 85:15; w/w) $100 \mathrm{~g}$, sugar powder $84 \mathrm{~g}$, shortening $84 \mathrm{~g}$, eggs $84 \mathrm{~g}$, baking powder $1.7 \mathrm{~g}$, calcium propionate $0.5 \mathrm{~g}$, glacial acetic acid $0.2 \mathrm{~mL}$, pineapple essence $0.4 \mathrm{~mL}$, water 25 $\mathrm{mL}$. PS-60/SSL $0.5 \mathrm{~g}$. WF-FSH blends, baking powder, calcium propionate were seived together. Shortening, sugar powder and emulsifiers were creamed for $1 \mathrm{~min}$ at $58 \mathrm{rpm}, 1 \mathrm{~min}$ at $112 \mathrm{rpm}$ and $3 \mathrm{~min}$ at $173 \mathrm{rpm}$ with a flat beater in a Hobart mixer (N-50, Ontario). Egg and essence were whipped with a whipper for 5 min at 173 rpm using a Hobart N-50 mixer. The whipped egg was added to the cream in parts while mixing for $3 \mathrm{~min}$ at 58 rpm until homogenous. The WF-FSH blend finally was 
added and mixed for 2 min at $58 \mathrm{rpm}$ along with the addition of acetic acid and water. The temperature of batter was $28^{\circ} \mathrm{C}$. The muffin batter $(65 \mathrm{~g})$ was added to cups in the cup cake pan and baked at $180^{\circ} \mathrm{C}$ for 30 min using the oven (Serial no. 965, APV, Queensland, and Australia). The volume of muffins was measured by rape seed displacement method [24]. The evaluation was done by judges having more than 10 years of experience in baking science \& technology. The trained panelists consisting of 15 people evaluated the muffins sample in individual taste booths as per ASTM (E2454-05, 2011) standards [25]. The evaluation was carried out by assigning scores for the following parameters: Cells (30), grain (16), texture (34), crumb colour (10) flavour (10) and Overall quality score (100) (AACC 10-90) [19].

\subsection{Texture Profile Analysis of Muffins}

The texture analyzer LR-5K (Lloyd Instruments Ltd., Hampshire, England) was used for measuring texture profile of muffins. The following conditions were set: load cell $5 \mathrm{~kg}$. Square shaped cake pieces measuring 5 $\mathrm{cm}$ on all sides with a sample thickness of $1 \mathrm{inch}, 80 \mathrm{~mm}$ diameter circular probe, $100 \mathrm{~mm} / \mathrm{min}$ cross head speed, $50 \%$ compression of the sample height. The data was analyzed using Nexygen 4.0 Software supplied along with the instrument. Hardness, chewiness, cohesiveness and springiness of muffins crumb were measured according to the method of Bourne [26].

\subsection{Composition of Muffins}

The moisture, ash, fat, protein and dietary fiber content of control and muffins with optimum level of FSH were carried out according to AOAC (2000) method [20]. The iron, calcium and zinc content of the muffins were estimated using atomic absorption spectrophotometer (AAS) according to the AOAC method (2000) [20].

\subsection{Statistical Analysis}

Statistical analysis of data was done by using Duncan's New Multiple Range Test as described by Steel and Torrie [27]. The experiments were carried out and results analyzed as per randomized block design with four replicates. The significant level was established at $\mathrm{p} \leq 0.05$.

\section{Results and Discussion}

Proximate analysis of FSH showed that the flour had moisture content of $11.7 \%$, ash $(2.9 \%)$, protein $(7.5 \%)$ and fat $(1.3 \%)$. The soluble and insoluble dietary fibre content was $45.56 \%$ and $31.2 \%$, respectively (Table 1). It is clear that, FSH is the main source of fiber. Similar results were also obtained in recent studies [14]. The data on wheat flour showed $11.90 \%$ moisture, $0.51 \%$ ash, $2.20 \%$ fat, $7.70 \%$ dry gluten, $310 \mathrm{sec}$. falling number and $8.60 \%$ protein.

WF-FSH blends were prepared by substituting FSH flour at $0,5 \%, 10 \%$ and $15 \%$ levels. The data on chemical characteristics showed that moisture and gluten content decreased whereas ash, protein and fat values increased marginally with increasing levels of FSH substitution (Table 2). Studies on fenugreek supplemented biscuits showed that addition of raw, soaked and germinated fenugreek flour to wheat flour increased the protein, lysine and dietary fiber contents [16].

Data on the influence of FSH and additives on the crumb colour of muffins is presented in Table 3. As the level of FSH increased in blends the lightness value of crumb decreased from 68.00 in control to 57.30 for muffins with $15 \% \mathrm{FSH}$. The $(+\mathrm{b})$ values representing yellowness increased from 17.63 of control to $21.00-23.00$ for muffins made with 5\% - 15\% FSH. Jyotsna et al., (2010) reported that higher "b" values in vermicelli prepared with fenugreek could be due to the carotene content of fenugreek seed [17]. Muffins with 10\% FSH considered optimum were treated with SSL and PS-60 showed increased lightness values indicating improve-

Table 1. Chemical composition of FSH.

\begin{tabular}{cc}
\hline Parameter & Value \\
\hline Moisture (\%) & $11.7 \pm 0.1$ \\
Total ash (g/100g) & $2.9 \pm 0.03$ \\
Protein (\%) & $7.5 \pm 0.02$ \\
Fat (\%) & $1.3 \pm 0.02$ \\
Soluble dietary fiber (\%) & $19.00 \pm 0.5$ \\
Insoluble dietary fiber (\%) & $25.87 \pm 0.6$ \\
\hline
\end{tabular}

Values are expressed as mean \pm Standard deviation.

Table 2. Chemical characteristics of WF-FSH blends.

\begin{tabular}{|c|c|c|c|c|c|}
\hline Flour blends WF:FSH & Total ash $(\%)$ & Dry gluten $(\%)$ & Falling number (secs) & Protein $(\%)$ & Fat $(\%)$ \\
\hline 100:0 & $0.51 \pm 0.03^{\mathrm{a}}$ & $7.70 \pm 0.03^{c}$ & $310 \pm 3.68^{\mathrm{a}}$ & $8.60 \pm 0.04^{b}$ & $2.20 \pm 0.03^{\mathrm{a}}$ \\
\hline $95: 5$ & $0.56 \pm 0.02^{\mathrm{b}}$ & $7.30 \pm 0.01^{\mathrm{b}}$ & $415 \pm 3.74^{b}$ & $8.53 \pm 0.05^{\mathrm{a}}$ & $2.12 \pm 0.03^{b}$ \\
\hline $90: 10$ & $0.68 \pm 0.02^{\mathrm{c}}$ & $7.00 \pm 0.02^{b}$ & $430 \pm 3.29^{c}$ & $8.45 \pm 0.36^{b}$ & $2.07 \pm 0.03^{\mathrm{c}}$ \\
\hline $85: 15$ & $0.76 \pm 0.02^{\mathrm{d}}$ & $6.80 \pm 0.03^{\mathrm{a}}$ & $440 \pm 2.44^{d}$ & $8.34 \pm 0.04^{b}$ & $2.02 \pm 0.02^{\mathrm{c}}$ \\
\hline
\end{tabular}

WF-FSH: Wheat flour-Fenugreek seed husk; Values are expressed as mean of three replicates. 
ment in colour of muffin crumb as against the muffin with $10 \%$ FSH only. Brockmole \& Zabik (1976) reported that when wheat bran was substituted in the cake formula, there was an increase in yellowness and redness but lightness value of the cake crumb decreased [28]. The results of our study are also in agreement with this report.

The data on the effect of FSH on physical characteristics of muffins are presented in Table 4 . As the level of FSH increased in the as blend as increase in batter density from $0.80-1.15 \mathrm{~g} / \mathrm{cc}$ was observed for $0 \%-15 \%$ FSH addition. The batter viscosity also increased from $32,500-38,000 \mathrm{cp}$ for $5 \%$ - 15\% FSH in blend. The volume of muffins increased marginally up to $10 \%$ level of FSH beyond which the volume of muffins decreased. The muffins containing 10\% FSH were considered optimum. The muffins made with $15 \%$ FSH had gummy mouth feel, lacked typical cohesiveness and hence were unacceptable. In order to improve the quality of muffins further, emulsifiers like sodium stearoyl lactylate (SSL) and polysorbate-60 (PS-60) were added at 0.5\% level. Both the emulsifiers had an improving effect on muffins. The batter density with emulsifiers showed a decrease indicating lighter batter and better air incorporation. The muffins with $10 \%$ FSH and PS-60 had a higher volume of $140 \mathrm{cc}$ than the muffins with $10 \% \mathrm{FSH}$ and SSL with a volume of 125 cc. PS-60 produced maximum im- provement in cakes followed by SSL and other emulsifiers like distilled glycerol monostearate, and sorbitan monostearate was reported [21].

Brockmole \& Zabik (1976) studied the substitution of wheat bran at $4 \%, 8 \%$ and $16 \%$ from 60 and $70 \%$ extraction flours in white cakes [28]. According to them the batter viscosity increased with increasing level of substitution and this increased viscosity could be due to the fibre constituents. Gilles (1960) stated that the increased viscosity could be due to the increased water absorption capacity of fiber constituents as a result of their large molecular size [29]. This increase in batter viscosity can also be attributed to the presence of gums in FSH. Ashwini et al. (2009) stated that there was an increase in batter viscosity of eggless cakes when hydrocollids like arabic, xanthan, guar, carrageenan and hydroxypropyl methyl cellulose were used [22]. Recently, Analia et al., (2012) reported that, the addition of maize resistant starch to wheat flour caused an increase of $5 \%$ in water absorption [10].

Effect of FSH and additives on the sensory characteristics of muffins is shown in Table 5. The control muffins had medium fine uniform cells with thin cell walls. The crumb colour of the control was creamish white with an overall quality score of 93.5 out of 100 . The muffins with $5 \%$ FSH had slightly uneven sized cells in the

Table 3. Influence of FSH on the crumb colour of muffins.

\begin{tabular}{|c|c|c|c|}
\hline & \multicolumn{3}{|c|}{ Muffins } \\
\hline & $\mathrm{L}$ & $\mathrm{a}$ & $\mathrm{b}$ \\
\hline \multicolumn{4}{|l|}{ WF:FSH muffin crumb } \\
\hline 100:00 & $68.00 \pm 0.50$ & $2.08 \pm 0.04$ & $17.63 \pm 0.01$ \\
\hline $95: 5$ & $61.20 \pm 0.30$ & $3.10 \pm 0.03$ & $21.00 \pm 0.24$ \\
\hline $90: 10$ & $59.40 \pm 0.20$ & $3.20 \pm 0.02$ & $22.00 \pm 0.33$ \\
\hline $85: 15$ & $57.30 \pm 0.20$ & $3.60 \pm 0.02$ & $23.00 \pm 0.23$ \\
\hline $90: 10+\operatorname{SSL}(0.5 \%)$ & $62.00 \pm 0.30$ & $3.30 \pm 0.02$ & $22.10 \pm 0.30$ \\
\hline $90: 10+$ PS-60 (0.5\%) & $63.00 \pm 0.30$ & $3.25 \pm 0.04$ & $22.50 \pm 0.30$ \\
\hline
\end{tabular}

WF-FSH: Wheat flour-Fenugreek seed husk; SSL: Sodium stearoyl lactylate; PS-60: Polysorbate 60. \#L: lightness/darkness; \pm a: red/blue; \pm b: yellow/green.

Table 4. Effect of FSH and additives on the physical characteristics of muffins.

\begin{tabular}{|c|c|c|c|}
\hline WF:FSH & Volume (cc) & Batter density (g/cc) & Batter viscosity $(\mathrm{cP})$ \\
\hline 100:0 & $80 \pm 0.01^{\mathrm{b}}$ & $0.80 \pm 0.05^{\mathrm{a}}$ & $32500 \pm 10.03^{\mathrm{a}}$ \\
\hline $95: 5$ & $90 \pm 0.04^{\mathrm{c}}$ & $0.85 \pm 0.03^{\mathrm{b}}$ & $33300 \pm 9.03^{c}$ \\
\hline $90: 10$ & $105 \pm 0.03^{\mathrm{c}}$ & $0.95 \pm 0.06^{\mathrm{d}}$ & $34000 \pm 5.03^{\mathrm{c}}$ \\
\hline $85: 15$ & $70 \pm 0.02^{\mathrm{a}}$ & $1.15 \pm 0.03^{\mathrm{e}}$ & $38000 \pm 8.03^{\mathrm{d}}$ \\
\hline $90: 10+\operatorname{SSL}(0.5 \%)$ & $125 \pm 0.03^{\mathrm{d}}$ & $0.90 \pm 0.02^{\mathrm{c}}$ & $33400 \pm 6.03^{\mathrm{c}}$ \\
\hline $90: 10+$ PS-60 $(0.5 \%)$ & $140 \pm 0.05^{\mathrm{e}}$ & $0.85 \pm 0.02^{\mathrm{b}}$ & $33150 \pm 7.03^{b}$ \\
\hline
\end{tabular}

WF-FSH: Wheat flour-Fenugreek seed husk; SSL: Sodium stearoyl lactylate: PS-60: Polysorbate-60. Mean score in a column with different super script letter are significant at $\mathrm{p}<0.05$ by DMRT. 
Table 5. Effect of substitution of FSH and additives on the sensory characteristics of muffins.

\begin{tabular}{ccccccc}
\hline Flour blends & Cells (30) & Grain (16) & Texture (34) & Crumb colour (10) & $\begin{array}{c}\text { Flavour (10) } \\
\text { Overall quality } \\
\text { score (100) }\end{array}$ \\
\hline WF:FSH & & & & & & \\
$100: 0$ & $28 \pm 0.05^{\mathrm{d}}$ & $14 \pm 0.04^{\mathrm{c}}$ & $32.5 \pm 0.03^{\mathrm{d}}$ & $9.5 \pm 0.04^{\mathrm{c}}$ & $9.5 \pm 0.03^{\mathrm{b}}$ & $93.5 \pm 0.63^{\mathrm{d}}$ \\
$95: 5$ & $27 \pm 0.02^{\mathrm{c}}$ & $13 \pm 0.03^{\mathrm{b}}$ & $31 \pm 0.04^{\mathrm{c}}$ & $9.0 \pm 0.06^{\mathrm{c}}$ & $9.5 \pm 0.41^{\mathrm{b}}$ & $89.5 \pm 0.32^{\mathrm{c}}$ \\
$90: 10$ & $26 \pm 0.06^{\mathrm{b}}$ & $11 \pm 0.06^{\mathrm{a}}$ & $30 \pm 0.02^{\mathrm{b}}$ & $8.0 \pm 0.02^{\mathrm{b}}$ & $9.0 \pm 0.32^{\mathrm{b}}$ & $84.0 \pm 0.08^{\mathrm{b}}$ \\
$85: 15$ & $24 \pm 0.04^{\mathrm{a}}$ & $10 \pm 0.03^{\mathrm{a}}$ & $28.5 \pm 0.05^{\mathrm{a}}$ & $6.5 \pm 0.05^{\mathrm{a}}$ & $7.0 \pm 0.06^{\mathrm{a}}$ & $76.0 \pm 0.62^{\mathrm{a}}$ \\
$90: 10+$ SSL (0.5\%) & $26.5 \pm 0.04^{\mathrm{b}}$ & $11.5 \pm 0.05^{\mathrm{a}}$ & $30.5 \pm 0.07^{\mathrm{b}}$ & $8.5 \pm 0.15^{\mathrm{b}}$ & $9.0 \pm 0.09^{\mathrm{b}}$ & $86.0 \pm 0.05^{\mathrm{b}}$ \\
$90: 10+$ PS-60 (0.5\%) & $27.0 \pm 0.03^{\mathrm{c}}$ & $12.5 \pm 0.01^{\mathrm{b}}$ & $31 \pm 0.2^{\mathrm{c}}$ & $9.0 \pm 0.12^{\mathrm{c}}$ & $9.0 \pm 0.04^{\mathrm{b}}$ & $88.5 \pm 0.91^{\mathrm{b}^{\mathrm{b}}}$ \\
\hline
\end{tabular}

WF-FSH: Wheat flour-Fenugreek seed husk; SSL: Sodium stearoyl lactylate; PS-60: Polysorbate 60. Mean score with different letter are significant at $\mathrm{p}<0.05$ by DMRT.

crumb grain and the texture was soft. The overall quality score was 89.5 out of 100 . The crumb of muffins with $10 \%$ FSH had slightly coarse cells with softer texture than muffins with $5 \%$ FSH with an overall quality score of 84 . The crumb of muffins containing $15 \%$ FSH had dense cells with thick cell walls. The crumb had dominant yellow color, the texture was too tender with gummy mouthfeel and the muffins were less cohesive and very fragile. As the muffins had foreign taste they were unacceptable. The muffins with $15 \%$ FSH had the lowest overall quality score of 76 . So the optimum level of incorporation of FSH was found to be $10 \%$ in muffins. These muffins when treated with SSL and PS- 60 at $0.5 \%$ level brought about improvement in grain and texture than muffins with $10 \%$ FSH only. The muffins with $10 \%$ FSH and PS-60 improved the overall quality significantly. The crumb cells in these muffins were medium fine, texture was soft and moist. The crumb colour was creamish white and muffins had overall quality score of 88.5 out of 100 . Hence addition of PS-60 at $0.5 \%$ to muffins with $10 \% \mathrm{FSH}$ produced good quality muffins.

The TPA of muffins prepared with different levels of FSH and additives are shown in Figure 1. As the level of FSH increased from $5 \%$ to $15 \%$ in muffins, there was a decrease in hardness, chewiness, springiness and cohesiveness value. At $15 \%$ level of FSH, the adverse effect was more pronounced. The muffins had lowest hardness and cohesiveness values indicating a tender and crumbly texture lacking the typical cohesiveness of the normal muffins. Use of additives SSL and PS-60 in muffins with optimum level of FSH (10\%) showed improving effect on the quality of muffins. However the improvement with PS-60 was significant as the muffins possessed good texture and medium fine grain. Kim and Walker reported that addition of PS-60 wheat starch batter in high ratio cake model system containing lactose produced the highest cake volume with best grain structure [29]. When substitution of wheat bran was increased from $4 \%$ to $16 \%$ in white layer cakes, tenderness of cakes

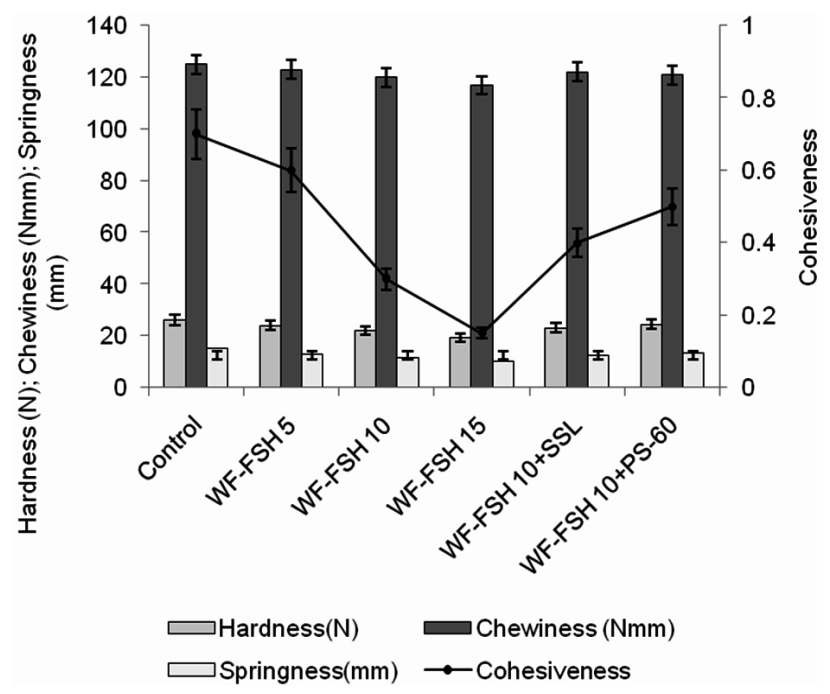

WF-FSH 5: $-5 \%$ Fenugreek seed husk in blend; WF-FSH 10: $-10 \%$ Fenugreek seed husk in blend; WF-FSH 15: $-15 \%$ Fenugreek seed husk in blend; WF-FSH 10 + SSL: Blend with Sodium Stearoyl-2-Lactylate; WF-FSH $10+$ PS-60: Blend with Polysorbate-60.

Figure 1. Texture profile analysis of muffins with FSH and additives.

increased and with increased levels the total amount of starch as well as gluten forming proteins became diluted [30]. Due to the dilution, the layer cake became less rigid and more tender. Similar effect was also evident in our studies.

Table 6 shows the composition of control muffins and muffin made with $10 \%$ FSH + PS-60. The data showed that the muffin with $10 \%$ FSH + PS-60 had 2.1 times more dietary fiber content than the control. Also, an increase in the iron, calcium and zinc content of muffins were observed.

\section{Conclusion}

Fenugreek seed husk is a rich source of dietary fiber and several important minerals. This fiber-rich functional ingredient can be incorporated in the manufacture of 
Table 6. Composition of muffins*.

\begin{tabular}{ccc}
\hline Parameters & Control Muffins & $\begin{array}{c}\text { WF:FSH + PS -60 } \\
(90: 10)\end{array}$ \\
\hline Moisture (\%) & $20.39 \pm 0.03$ & $21.62 \pm 0.04$ \\
Total ash (g/100 g) & $1.06 \pm 0.03$ & $1.16 \pm 0.03$ \\
Protein (\%) & $7.26 \pm 0.02$ & $7.97 \pm 0.03$ \\
Fat (\%) & $31.94 \pm 0.04$ & $29.00 \pm 0.02$ \\
Total Dietary Fiber (\%) & $6.50 \pm 0.02$ & $13.36 \pm 0.04$ \\
Iron (mg) & $1.10 \pm 0.05$ & $1.40 \pm 0.04$ \\
Calcium (mg) & $16.50 \pm 1.00$ & $18.00 \pm 1.00$ \\
Zinc (mg) & $0.34 \pm 0.05$ & $0.60 \pm 0.04$ \\
\hline
\end{tabular}

*Per $100 \mathrm{~g}$ of muffins Values are means of three replicates \pm standard deviation WF-FSH: Wheat flour-Fenugreek seed husk; PS-60: Polysorbate 60.

high-fiber muffins. FSH flour can be optimally incorporated at $10 \%$ level to wheat flour in the preparation of good quality high-fiber muffins. Use of polysorbate-60 at $0.5 \%$ level along with $\mathrm{FSH}$ at $10 \%$ level in these muffins improved the overall quality characteristics of muffins significantly. The fiber-rich muffins possessed good volume, soft texture and medium-fine grain with twice amount of DF.

\section{Acknowledgements}

Authors thank the Director, CFTRI, and Mysore, India for his keen interest in this work and for the facilities provided. The financial support from CSIR, New Delhi is gratefully acknowledged.

\section{REFERENCES}

[1] S. Lee, G. E. Inglett and C. J. Carriere, "Effect of Nutrium Oat Bran and Flaxseed on Rheological Properties of Cakes," Cereal Chemistry, Vol. 81, No. 5, 2004, pp. 637642. doi:10.1094/CCHEM.2004.81.5.637

[2] C. C. Lee and S. D. Lin, "Effect of GABA Tea on Quality Characteristics of Chiffon Cake," Cereal Chemistry, Vol. 85, No. 1, 2008, pp. 31-38. doi:10.1094/CCHEM-85-1-0031

[3] T. D. Gordon, "Functional Properties vs Physiological Action of Total Dietary Fiber," Cereal Food World, Vol. 34, No. 7, 1989, pp. 517-525.

[4] D. Kromhout, E. B. Bosschieter and C. De Lezenne Coulander, "Dietary Fibre and 10-Year Mortality from Coronary Heart Disease, Cancer, and All Causes. The Zutphen Study," Lancet, Vol. 320, No. 8297, 1982, pp. 518-522. doi:10.1016/S0140-6736(82)90600-6

[5] D. Kritchevsky, "Caloric Restriction and Cancer," Journal of Nutrition Science Vitaminology (Tokyo), Vol. 47, No. 1, 2001, pp. 13-19. doi:10.3177/jnsv.47.13

[6] C. G. Humble, A. M. Malarcher and H. A. Tyroler, "Dietary Fiber and Coronary Heart Disease in Middle-Aged Hypercholesterolemic Men," Americian Journal of Pre- ventive Medicine, Vol. 9, No. 4, 1993, pp. 197-202.

[7] M. L. Wheeler and F. X. Pi-Sunyer, "Carbohydrate Issues: Type and Amount," Journal of the American Dietetic Association, Vol. 108, No. 4, 2008, pp. S34-S39. doi:10.1016/j.jada.2008.01.024

[8] J. Y. Thebaudin, A. C. Lefebvre, M. Harrington and C. M. Bourgeois, "Dietary Fibres: Nutritional and Technological Interest," Trends in Food Science Technology, Vol. 8, No. 2, 1997, pp. 41-48. doi:10.1016/S0924-2244(97)01007-8

[9] D. M. Lebesi and C. Tzia, "Effect of the Addition of Different Dietary Fiber and Edible Cereal Bran Sources on the Baking and Sensory Characteristics of Cupcakes," Food Bioprocess Technology, Vol. 4, No. 5, 2011, pp. 710-722. doi:10.1007/s11947-009-0181-3

[10] G. V. Analía, B. Diana, T. C. Carmen, A. C. María and P. C. María, "Emulsifiers: Effects on Quality of Fibre-Enriched Wheat Bread," Food and Bioprocess Technology, 2012 (online). doi:10.1007/s11947-011-0772-7

[11] H. Anna-Sophie, W. Anika, C. Mariko, B. Jurgen, Z. Emanuele, A. K. Elke and C. Michael, "Investigation of Product Quality, Sensory Profile and Ultrastructure of Breads Made from a Range of Commercial Gluten-Free Flours Compared to Their Wheat Counterparts," European Food Research Technology, Vol. 235, No. 2, 2012, pp. 333-344. doi:10.1007/e00217-012-1763-2

[12] E. Altuntas, E. O. Zgo and O. F. Taser, "Some Physical Properties of Fenugreek (Trigonella foenum-graceum L.) Seeds," Journal of Food Engineering, Vol. 71, 2006, pp. 37-43.

[13] K. Srinivasan, "Fenugreek (Trigonella foenum-graecum): A Review of Health Beneficial Physiological Effects," Food Review International, Vol. 22, No. 2, 2006, pp. 203-224. doi:10.1080/87559120600586315

[14] M. M. Naidu, B. N. Shyamala, J. P. Naik, G. Sulochanamma and P. Srinivas, "Chemical Composition and Antioxidant Activity of the Husk and Endosperm of Fenugreek Seeds," LWT-Food Science and Technology, Vol. 44, No. 2, 2011, pp. 451-456.

[15] H. R. Sharma and G. S. Chauhan, "Physico-Chemical and Rheological Quality Characteristics of Fenugreek (Trigonella foenum graccum L.) Supplemented Wheat Flour," Journal of Food Science and Technology, Vol. 37, No. 1, 2000, pp. 87-90.

[16] S. Hooda and S. Jood, "Organoleptic and Nutritional Evaluation of Wheat Biscuits Supplemented with Untreated and Treated Fenugreek Flour," Food Chemistry, Vol. 90, No. 3, 2005, pp. 427-435. doi:10.1016/j.foodchem.2004.05.006

[17] R. Jyotsna, D. Indrani, R. S. Manohar and G. Venkateswara Rao "Effect of Fenugreek on the (Trigonella foenum-graecum L.) on the Textural Characteristics and Microstructure of Vermicelli from Triticum Durum Wheat Semolina," Journal of Food Processing and Preservation, Vol. 35, No. 3, 2011, pp. 320-326. doi:10.1111/j.1745-4549.2009.00459.x

[18] D. Indrani, R. Jyotsna and G. Venkateswara Rao, "Influence of Fenugreek Seed Powder on the Dough Rheology, Microstructure and Quality of Parotta-An Indian Flat 
Bread," Journal of Textural Studies, Vol. 41, No. 2, 2010, pp. 208-223. doi:10.1111/j.1745-4603.2010.00222.x

[19] American Association of Cereal Chemists (AACC), "Approved Methods of American Association of Cereal Chemists," 9th Edition, St. Paul, Minnesota, 2000, Method Nos. 44-15, 08-01, 38-10, 56-81B, 46-10, 10-90.

[20] Association of Official Analytical Chemists (AOAC), "Total Soluble and Insoluble Dietary Fibre in Foods (991.43)," 17th Edition, AOAC International, Gainthersburg, 2000.

[21] R. Jyotsna, P. Prabhasankar, D. Indrani and G. Venkateswara Rao, "Improvement of Rheological and Baking Properties of Cake Butters with Emulsifier Gels," Journal of Food Science, Vol. 69, No. 1, 2004, pp. 16-19.

[22] A. Ashwini, R. Jyotsna and D. Indrani, "Effect of Hydrocolloids and Emulsifiers on the Rheological, Microstructural and Quality Characteristics of Eggless Cakes," Food Hydrocolloids, Vol. 23, No. 3, 2009, pp. 700-707. doi:10.1016/i.foodhyd.2008.06.002

[23] R. Jyotsna, C. Soumya, D. Indrani and G. Venkateswara, Rao, "Effect of Replacement of Wheat Flour with Finger Millet (Eleusine corcana L.) on the Batter Microscopy, Rheology and Quality Characteristics of Muffins," Journal of Textural Studies, Vol. 42, No. 6, 2011, pp. 478-489. doi:10.1111/j.1745-4603.2011.00309.x
[24] M. Soumya, T. Jeyarani, R. Jyotsna and D. Indrani, "Effect of Replacement of Fat with Sesame Oil and Additives on Rheological, Microstructural, Quality Characteristics and Fatty Acid Profile of Cakes," Food Hydrocolloids, Vol. 23, No. 7, 2009, pp. 1827-1836. doi:10.1016/j.foodhyd.2009.02.008

[25] American Society for Testing of Materials (ASTM) "E 2454-05 (2011) Standard Guide for Sensory Evaluation Method to Determine the Sensory Shelf-Life of Consumer Products," Vol. 15.08, Pennsylvania, 2011.

[26] M. C. Bourne, "Texture Profile Analysis," Food Technology, Vol. 32, 1978, pp. 62-66.

[27] R. G. D. Steel and JH. Torrie, "Principles and Procedures of Statistics," McGraw Hill, New York, 1960, pp. 99-131.

[28] C. L. Brock Mole and M. E. Zabik, "Wheat Bran and Middlings in White Layer Cakes," Journal of Food Science, Vol. 41, No. 2, 1976, pp. 357-360.

[29] K. A. Gilles, "The Present Status of the Role of Pentosans in Wheat Flour Quality," Baker's Digest 34, 1960, p. 47.

[30] C. S. Kim and C. E. Walker, "Interactions between Starches, Sugars and Emulsifiers in High Ratio Cake Model Systems," Cereal Chemistry, Vol. 69, No. 2, 1992, pp. 206-212. 